\title{
PELATIHAN DESAIN GRAFIS MENGGUNAKAN APLIKASI CANVA TINGKAT SMK DI SMKN 1 GUNUNG PUTRI BOGOR
}

\author{
Tiawan, Musawarman, Luthfiyah Sakinah, Nopi Rahmawati, Hamzah Salman \\ Politeknik Enjinering Indorama, Indonesia \\ tiawan@pei.ac.id
}

\begin{abstract}
Following the title of this community service program, the application of science and technology is the introduction of graphic design training for students of SMKN 1 Gunung Putri Bogor. Skills training activities are supported by lectures, questions, and answers and of course direct practice in the computer laboratory of SMKN 1 Gunungputri Bogor. The training module will be given to participants as a tool in practical activities in the computer laboratory of SMKN 1 Gunung Putri in the online form (.pdf). The purpose of implementing this community service program is to improve Graphic Design skills by using the Canva application for students. From the results of the evaluation and findings that we obtained during the implementation of this PKM activity, we can conclude that this PKM program has been able to provide enormous benefits and is right on target for the audience of students / myself as training participants who are the targets of this activity. This form of training is a very effective form of providing refresher and additional insights and new knowledge in the field of graphic design in the school learning process.
\end{abstract}

Keywords: Training, Community Service, Graphic Design, Canva.

\begin{abstract}
Abstrak
Sesuai dengan judul program pengabdian masyarakat ini, metode penerapan ipteks yang dilakukan adalah berbentuk pelatihan pengenalan Desain Grafis menggunakan canva untuk Siswa/I SMKN 1 Gunung Putri Bogor. Kegiatan pelatihan keterampilan ditunjang dengan ceramah, tanya jawab dan tentu saja praktek secara langsung di laboratorium Komputer SMKN 1 Gunungputri Bogor. Modul pelatihan akan diberikan kepada peserta sebagai alat bantu dalam kegiatan praktek di laboratorium komputer SMKN 1 Gunung Putri dalam bentuk online (.pdf). Tujuan dari pelaksanaan program pengabdian masyarakat ini adalah untuk meningkatkan keterampilan Desain Grafis dengan menggunakan aplikasi Canva bagi siswa/i. Dari hasil evaluasi serta temuan-temuan yang kami peroleh selama pelaksanaan kegiatan PKM ini, dapat kami simpulkan bahwa program PKM ini telah mampu memberikan manfaat yang sangat besar dan tepat sasaran bagi khalayak siswa/I peserta pelatihan yang menjadi sasaran dalam kegiatan ini. Bentuk pelatihan seperti ini merupakan bentuk yang sangat efektif untuk memberikan penyegaran dan tambahan wawasan serta pengetahuan baru di bidang desain grafis di dalam proses pembelajaran sekolah.
\end{abstract}

Kata Kunci: Pelatihan, Pengabdian Kepada Masyarakat, Desain Grafis, Canva.

Submitted: $2020-08-26$

Revised: $2020-09-30$

Accepted: 2020-10-03

\section{Pendahuluan}

Pendidikan sebagai bagian dari sistem kehidupan di masyarakat tidak dapat dilepaskan dari perkembangan dan perubahan yang terjadi di masyarakat itu sendiri. Perubahan struktur dunia kerja yang diakibatkan pesatnya perkembangan ilmu pengetahuan dan teknologi serta diberlakukannnya era global menuntut lembaga 
pendidikan untuk benar-benar menghasilkan lulusan yang berkualitas dan memiliki daya saing kuat.

Salah satu bagian kesenian yang penerapannya berbentuk dua atau tiga dimensi, dikenal dengan istilah seni rupa. Seni rupa merupakan ungkapan gagasan dan perasaan manusia yang diwujudkan melalui pengolahan media dan penataan elemen (yang meliputi unsur titik, garis, warna, bidang, tekstur, gelap terang) serta prinsip-prinsip desain. Seni rupa merupakan realisasi dari sebuah imajinasi tanpa batas dan tidak ada batasan, sejatinya, dalam berkarya seni tidak akan kehabisan ide dan imajinasi.

Perancang grafis atau sering disebut dengan desainer grafis (bahasa Inggris: graphic designer) adalah profesi yang berhubungan dengan ilustrasi, tipografi, fotografi, atau graphic motion/gambar bergerak/ animasi. Seorang desainer grafis menciptakan karya untuk (misalnya: penerbit, media cetak, elektronik, dan lain-lain), termasuk di dalamnya brosur dan iklan suatu produk. Mereka bertanggung jawab untuk sebuah tampilan agar tampak menarik, yang bisa diaplikasikan dalam berbagai bentuk materi promosi yang berkaitan dengan produk dan publik. Perancang grafis bertugas untuk menyampaikan sebuah informasi yang diinginkan oleh produk/klien dalam bentuk desain yang menarik. Kata desain memiliki arti merancang atau merencanakan. Kata grafis sendiri mengandung dua pengertian: (1) graphien (Latin = garis, marka) yang kemudian menjadi graphic arts atau komunikasi grafis, (2) graphise vakken (Belanda = pekerjaan cetak) yang di Indonesia menjadi grafika, diartikan sebagai percetakan. Jadi, pengertian desain grafis adalah pekerjaan dalam bidang komunikasi visual yang berhubungan dengan grafika (cetakan) dan/ atau pada bidang dua dimensi, dan statis (tidak bergerak dan bukan time-based image). Secara khusus, desain grafis adalah keahlian menyusun dan merancang unsur visual menjadi informasi yang dimengerti publik/masyarakat. Bidang profesi desain grafis menangani konsep komunikasi grafis, merancang, dan meyelaraskan unsur yang ditampilkan dalam desain (huruf, gambar, dan atau foto, elemen grafis, warna) sesuai dengan tujuan komunikasi, dan mengawasi produksi (cetak). Dalam kerjanya, desainer grafis memberi brief dan pengarahan kepada ilustrator atau fotografer agar hasil yang diperoleh sesuai dengan rancangan desainnya.

Dalam rangka meningkatkan kemampuan siswa/I SMKN 1 Gunung Putri dalam penguasaan desain grafis salah satunya yaitu menggunakan aplikasi canva, maka diperlukan pelatihan materi yang relevan dan intensif. Pelatihan diselenggarakan di laboratorium komputer lingkungan sekolah SMKN 1 Gunung Putri Bogor dalam bentuk Pengabdian Kepada Masyarakat (PKM).

\section{Metode}

Metode yang digunakan untuk mencapai tujuan dan target yang diharapkan adalah dengan Ceramah, Tanya Jawab dan Praktek. Materi yang diberikan yaitu Penggunaan aplikasi canva mulai dari membuat logo, poster, infografik dan CV yang menarik serta mengembangkan bakat yang ada dalam siswa dalam bidang technopreneur desain grafis. Tahapan pelaksanaan kegiatan ini dapat digambarkan dengan langkah-langkah sebagai berikut : 


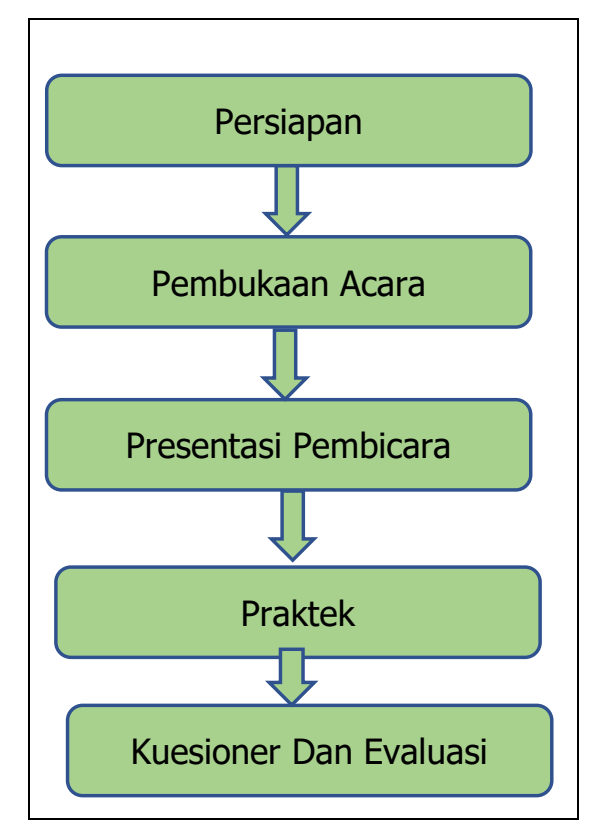

Gambar 1. Langkah Pelaksanaan Kegiatan

Khalayak sasaran pengabdian masyarakat ini adalah siswa/I SMKN 1 Gunung Putri Bogor. Untuk kepentingan layanan pengabdian dan ketersediaan sarana dan prasarana maka sebanyak 42 siswa/I SMKN 1 Gunung Putri Bogor menggunakan laboratorium computer SMKN 1 Gunung Putri Bogor.

\section{Hasil dan Pembahasan}

Pengabdian pada masyarakat bagi siswa/I SMKN 1 Gunung Putri Bogor dilaksanakan pada hari/tanggal Kamis, 09 Januari 2020, pukul 13.00 - 15.00 WIB. Pengabdian pada masyarakat dilaksanakan di Laboratorium Komputer di SMKN 1 Gunung Putri Bogor.

Hasil yang diperoleh dari pengabdian ini adalah sebagai berikut.

1. Peserta yang hadir pada acara pengabdian itu sejumlah 42 orang siswa/i.

2. Materi yang diberikan pada pengabdian ini meliputi materi Canva meliputi pengenalan canva, mendaftar canva, pembuatan poster sekolah menggunakan template, mendesain Curriculum Vitae, tips trick canva dan penggunaan canva dalam social media.

3. Para peserta yang mengikuti pelatihan merasa senang dan puas dengan kegiatan pengabdian ini, hal ini terlihat dari ungkapan kepuasan serta keantusiasan peserta mendengarkan dan bertanya berbagai hal tentang materi yang telah diberikan oleh para pengabdi.

4. Kegiatan pengabdian ini dianggap oleh peserta sebagai sarana pengenalan dan pembelajaran mengenai aplikasi Canva.

5. Pada acara penutupan, hampir seluruh para peserta mengharapkan agar program serupa diadakan kembali untuk lebih memahami mengenai aplikasi canva. 
BERNAS:

Jurnal Pengabdian Kepada Masyarakat

Vol.1 No. 4, October 2020 , pp. $476-480$

Tabel 1. Hasil Penilaian Kuisioner Kegiatan 2 PkM

\begin{tabular}{|c|c|c|}
\hline No & Aspek Penilaian & Skor Nilai \\
\hline 1 & Kepuasan peserta mengikuti kegiatan PkM & $87,8 \%$ \\
\hline 2 & $\begin{array}{l}\text { Adanya perubahan sikap, pengetahuan dan keterampilan setelah } \\
\text { mengikuti kegiatan PkM }\end{array}$ & $80,5 \%$ \\
\hline 3 & $\begin{array}{l}\text { Pemanfaatan ilmu pengetahuan dan teknologi yang telah dibagikan secara } \\
\text { berkelanjutan }\end{array}$ & $73,2 \%$ \\
\hline 4 & $\begin{array}{l}\text { Peserta kegiatan dapat mempraktekkan Ilmu pengetahuan dan teknologi } \\
\text { yang di dapat dari kegiatan PKM }\end{array}$ & $78 \%$ \\
\hline 5 & $\begin{array}{l}\text { Dapat membantu permasalahan yang dimiliki peserta seputar materi yang } \\
\text { diberikan lewat kegiatan PkM }\end{array}$ & $82,9 \%$ \\
\hline 6 & Umpan Balik untuk mengadakan kegiatan PkM kembali & $92,7 \%$ \\
\hline
\end{tabular}

Interval penilaian kepuasan adalah sebagai berikut :

$\begin{array}{ll}\text { Indeks } 80 \%-100 \% & \text { : Sangat Puas } \\ \text { Indeks } 60 \%-79,99 \% & \text { : Puas } \\ \text { Indeks } 40 \%-59,99 \% & \text { : Cukup Puas } \\ \text { Indeks } 20 \%-39,99 \% & \text { : Kurang Puas } \\ \text { Indeks } 0 \%-19,99 \% & \text { : Tidak Puas }\end{array}$

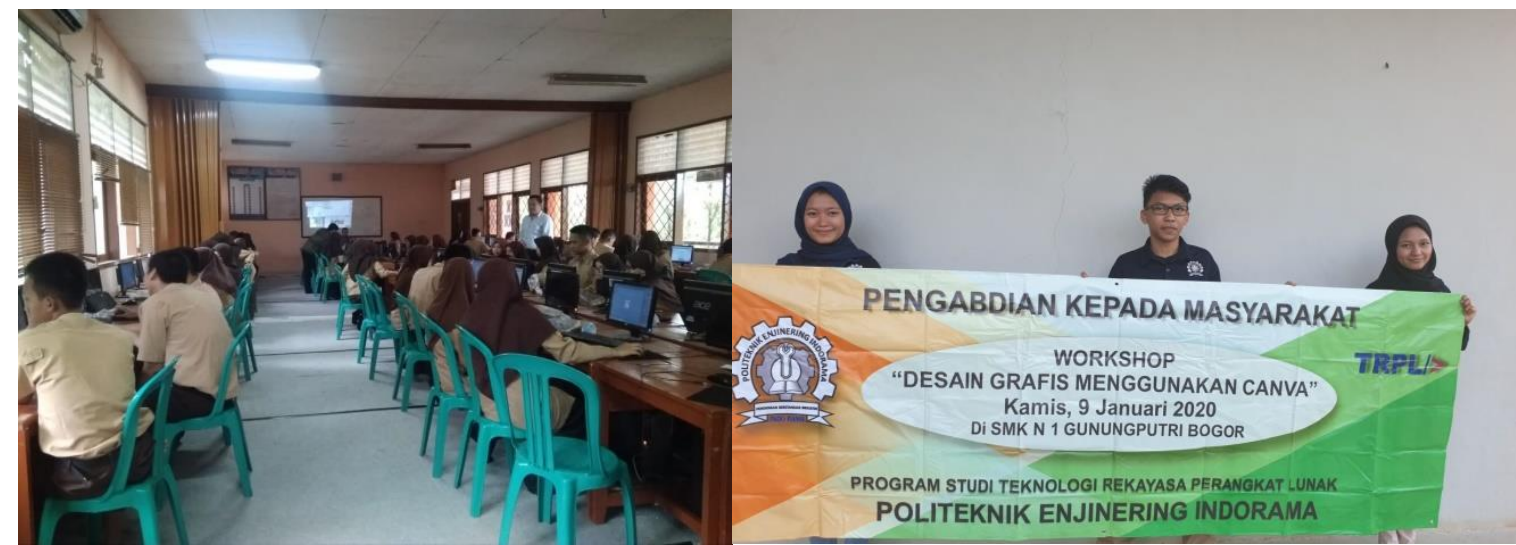

Gambar 2. Pelaksanaan Kegiatan PkM

Secara umum kegiatan pengabdian ini berjalan lancar, dimulai dari kegiatan survey pendahuluan, pelaksanaan kegiatan pegabdian, sampai kepada penyusunan laporan. Berdasarkan diskusi yang diselenggarakan diperoleh kesimpulan bahwa para peserta pengabdian tersebut merasa senang dan puas. Hal ini terbukti dengan adanya permintaan dari para peserta agar kegiatan pengabdian ini tidak hanya diselenggarakan satu kali tetap harus berkelanjutan. Melalui pengabdian yang berkelanjutan akan terjalin hubungan kerjasama antara Politeknik Enjinering Indorama dengan SMKN 1 Gunung Putri Bogor. Hubungan kerjasama dalam hal pengembangan desain grafis untuk siswa/I SMKN 1 Gunung Putri Bogor sehingga program pengabdian masyarakat dapat berjalan maksimal, yang menjadi salah satu kewajiban civitas akademika Politeknik Enjinering Indorama. 


\section{Kesimpulan}

Berdasarkan uraian pelaksanaan kegiatan pengabdian ini, maka dapat ditarik kesimpulan sebagai berikut.

1. Kegiatan pengabdian ini dapat dikategorikan berhasil dari segi partisipasi peserta mengingat dihadiri oleh 42 orang siswa/I SMKN 1 Gunung Putri Bogor.

2. Peserta pengabdian sangat merasa senang dan puas dengan kegiatan pengabdian dan meminta agar pengabdian serupa dilaksanakan berkesinambungan mengingat pelatihan aplikasi Canva ini sangat membantu siswa/I SMKN 1 Gunung putri dalam kebutuhan desain grafis di penggunaan sehari-hari.

3. Berdasarkan uraian pelaksanaan kegiatan pengabdian ini, dapat disimpulkan bahwa partisipasi peserta pengabdian sebesar $90 \%$, peserta aktif mengikuti kegiatan dan mengekspresikan sikap senang dan puas

4. Dengan kegiatan pengabdian. Sikap itu ditunjukkan oleh permintaan agar pengabdian serupa dilaksanakan kembali dengan program training desain grafis tingkat lanjut.

5. Para peserta merasa memperoleh wawasan baru tentang penggunaan aplikasi canva.

\section{Daftar Pustaka}

A Stevenson, George. (1992). Graphic Arts Encyclopedia. New York: Design Press.

Ariyus, S. D. (2007). Interaksi Manusia Dan Komputer. Yogyakarta: Andy Offset.

Arthur, Rene. (2009). Desain Grafis: dari mata turun ke hati. Bandung: Penerbit Kelir.

Darmaprawira W.A. Sulasmi. (2002). Warna: teori dan kreativitas penggunaannya ed. Ke2. Bandung: ITB.

Gill, Martha. (2006). Color Harmony, A Guide to Creative Color Combinations. USA: Rockport Publishers.

Sean Adams, Terry Stone, Noreen Morioka. (2006). Color Design Workbook: A Real World Guide to Using Color in Graphic Design. Rockport Publishers.

Sihombing, Danton. (2001). Tipografi Dalam Desain Grafis. Jakarta: Gramedia

Sudjana, N. (2010). Penilaian Hasil Proses Belajar Mengajar. Bandung: PT. Remaja Rosdakarya.

Sugiyono. (2017). Metode Penelitian Kuantitatif, Kualitatif, dan R\&D. Bandung : Alfabeta, CV.

Sugiyono. (2012). Memahami Penelitian Kualitatif. Bandung: ALFABETA

https://www.canva.com/ [Diakses 20 Januari 2020]

https://www.canva.com/id id/cerita/ [Diakses 20 Januari 2020] 